\title{
Does Irritation Induced by Charitable Direct Mailings Reduce Donations?
}

\section{Merel van Diepen, Bas Donkers and Philip Hans Franses}

Version March 2009

\begin{tabular}{|l|l|}
\hline \multicolumn{2}{|l|}{ ERIM REPORT SERIES RESEARCHINMANGEMENT } \\
\hline ERIM Report Series reference number & ERS-2008-036-MKT \\
\hline Publication & March 2009 \\
\hline Number of pages & 36 \\
\hline Persistent paper URL & http://hdl.handle.net/1765/12704 \\
\hline Email address corresponding author & donkers@ese.eur.nl \\
\hline Address & Erasmus Research Institute of Management (ERIM) \\
& RSM Erasmus University / Erasmus School of Economics \\
& Erasmus Universiteit Rotterdam \\
& P.O.Box 1738 \\
& 3000 DR Rotterdam, The Netherlands \\
& Phone: + 31 10 408 1182 \\
& Fax: + 31 10 408 9640 \\
& Email: info@erim.eur.nl \\
& Internet: www.erim.eur.nl \\
\hline
\end{tabular}

Bibliographic data and classifications of all the ERIM reports are also available on the ERIM website: www.erim.eur.nl 
ERASMUS RESEARCH INSTITUTE OF MANAGEMENT

\section{REPORT SERIES}

\section{RESEARCH IN MANAGEMENT}

\begin{tabular}{|c|c|}
\hline \multicolumn{2}{|c|}{ ABSTRACT AND KEYWORDS } \\
\hline Abstract & $\begin{array}{l}\text { Charities mainly rely on direct mailings to attract the attention of potential donators. Individuals } \\
\text { may feel irritated by these mailings, in particular when they receive many mailings. This might } \\
\text { harm the revenues charities receive from their mailing activities. Moreover, target selection by } \\
\text { charities likely results in many mailings being sent to the best donators and hence they might } \\
\text { also be most irritated. As such, irritation with direct mailings could well be endogenously } \\
\text { determined. To ensure exogenous variation in irritation, we performed a unique controlled field } \\
\text { experiment in cooperation with five of the largest charities in the Netherlands. Our analysis } \\
\text { reveals that direct mailings do result in irritation, but surprisingly this affects neither stated nor } \\
\text { actual donating behavior. }\end{array}$ \\
\hline Free Keywords & direct marketing, irritation, charity donations, field experiment \\
\hline Availability & $\begin{array}{l}\text { The ERIM Report Series is distributed through the following platforms: } \\
\text { Academic Repository at Erasmus University (DEAR), DEAR ERIM Series Portal } \\
\text { Social Science Research Network (SSRN), SSRN ERIM Series Webpage } \\
\text { Research Papers in Economics (REPEC), REPEC ERIM Series Webpage }\end{array}$ \\
\hline Classifications & $\begin{array}{l}\text { The electronic versions of the papers in the ERIM report Series contain bibliographic metadata } \\
\text { by the following classification systems: } \\
\text { Library of Congress Classification, (LCC) LCC Webpage } \\
\text { Journal of Economic Literature, (JEL), JEL Webpage } \\
\text { ACM Computing Classification System CCS Webpage } \\
\text { Inspec Classification scheme (ICS), ICS Webpage }\end{array}$ \\
\hline
\end{tabular}




\title{
Does Irritation Induced by Charitable Direct Mailings Reduce Donations? ${ }^{1}$
}

\author{
March 2009
}

Merel van Diepen

Erasmus Research Institute of Management \& Econometric Institute

Erasmus University Rotterdam

\author{
Bas Donkers $^{2}$ \\ Department of Business Economics \\ Erasmus University Rotterdam
}

Philip Hans Franses

Econometric Institute

Erasmus University Rotterdam

\footnotetext{
${ }^{1}$ We would like to thank the charitable organizations that cooperated in the field experiment, Acxiom Netherlands, Jacoline Brouwer and Peter Exterkate for assistance in data preparation and the editor, area editor and two anonymous reviewers for their helpful comments.

2 Address for correspondence: B. Donkers, Department of Business Economics, Erasmus University Rotterdam, P.O. Box 1738, NL-3000 DR Rotterdam, The Netherlands, tel.nr. +31104082411, e-mail: donkers@ese.eur.nl
} 


\title{
Does Irritation Induced by Charitable Direct Mailings Reduce Donations?
}

\begin{abstract}
Charities mainly rely on direct mailings to attract the attention of potential donators. Individuals may feel irritated by these mailings, in particular when they receive many mailings. This might harm the revenues charities receive from their mailing activities. Moreover, target selection by charities likely results in many mailings being sent to the best donators and hence they might also be most irritated. As such, irritation with direct mailings could well be endogenously determined. To ensure exogenous variation in irritation, we performed a unique controlled field experiment in cooperation with five of the largest charities in the Netherlands. Our analysis reveals that direct mailings do result in irritation, but surprisingly this affects neither stated nor actual donating behavior.
\end{abstract}

Keywords: Direct marketing; Irritation; Charity donations; Field experiment 


\section{Introduction}

Charities rely heavily on direct mailings to attract the attention of potential donators. In addition, billboard, television and radio advertising, as well as online activities, are used, but direct mailings by far outnumber other commercial efforts. Much attention is paid to the design of the printed material, the catch phrases and the wording. The careful attention paid to the content of solicitation letters, however, has not been able to avoid a strong association between charitable direct mailings and what is known as "junk mail”. The large number of charities sending out direct mailings, and the volumes at which they do this, results in self-stated annoyance towards the charities and their direct mailing activities for more than 60\% of the population (TNS NIPO, 2003, NFP Synergy, 2004). Although people often see the value of charities, they also believe the charities are overdoing it and are wasting paper and time.

A potential consequence of irritation is that individuals cut their donations to charity or even stop donating completely. Obviously, and most importantly, this reduces revenues. Another effect is that the databases of charities become less useful for future target selection. So, for charities it is important to understand what happens when people get irritated. Existing literature, however, only provides evidence for charitable direct mail irritation, but there is no detailed study on its behavioral consequences, especially not on actual donating behavior. Diamond and Noble (2001) get close as they use a survey to elicit respondents’ general response behavior towards direct mailings.

Although data collection through a survey is a natural strategy to measure levels of irritation and response behavior, there also is a clear drawback of this approach. Indeed, individuals may misrepresent their actual behavior, as answers to questions on how much people actually donate could be subject to a social desirability bias (Burt and Popple, 1998). In addition, individuals might not recall exactly how many mailings they received. To meet these drawbacks, the approach we take in this paper is to compare stated measures of irritation with actual donating behavior. Moreover, as charities compete and hence individuals may receive multiple mailings from multiple charities in short stretches of time, we design a natural field experiment in which we create 
controlled variation in the number of mailings individuals receive. This permits us to investigate the impact of direct mailings and irritation in a realistic setting within the appropriate subject pool (see List and Reiley, 2008). To carry out this natural field experiment, we obtained cooperation of five of the largest charities in the Netherlands.

To ensure a proper causal interpretation of the relationships between mailing pressure, irritation and behavior, we focus on dependent variables that are measured in the future, compared to the timing of the independent variables. More specific, we first carry out the field experiment to create exogenous variation in mail pressure. We then measure irritation with a survey, where irritation is a potential consequence of increased mail pressure. Finally, the effect of irritation on behavior is analyzed using behavior in a time period following the survey. Combining the abovementioned sources of information, properly spaced in time, provides us with a unique database. Moreover, our analysis results in a surprising conclusion. While people do claim to get irritated by direct mailings, and that they get more irritated by more mailings, such irritation affects neither stated nor actual donating behavior.

The remainder of this paper is organized as follows. Before we arrive at our data analysis and results, we first provide a discussion of the relevant literature. Then we discuss the data collection and our statistical methodology. After studying the potential impact of mere-measurement effects, we conclude with a discussion of the main results.

\section{Background}

Potential donators nowadays feel overwhelmed by many direct mailings from many charities (Abdy and Barclay 2001, Sargeant and Kähler 1999) and this may lead to “donor fatigue” (Andreoni 2006). The term junk mail surfaces frequently in reference to direct mailings. These unwanted exposures may cause irritation, which in turn could influence behavior, for example by reducing charitable donations.

Over the past decades, companies have continuously increased their use of direct marketing, with direct mail as the most important direct marketing activity of all (Direct Marketing Association 2007). One type of company that is known for making extensive use of direct print mail is charities (Francis and Holland 1999). 
As each direct mail provides an individual with an opportunity to donate, it may seem appealing to send direct mailings at high frequencies. The more mailings, the higher is the probability that at least one mailing will not be overlooked in the large amounts of mail or simply discarded out of lack of interest at the time of receipt. Similarly, repeated advertising exposures can lead to familiarity and liking of a company and can prevent forgetting over time (Zajonc 1968; Zielske 1959). Direct mailings can thus serve as a reinforcement of the message. Indeed, the amount of charitable direct mailings is unabatedly on the rise (Direct Marketing Association 2007). At the same time, more mailings will also be more costly, while revenues cannot be expected to increase forever (see Simester, Hu, Brynjolfsson and Anderson (2009) for evidence in the context of direct mail catalogs). In that sense, there will be decreasing marginal revenues from sending more mailings, most likely driven by decreasing marginal utility of donating more money or by increasing opportunity costs.

Despite the obvious relevance of the subject, not much research has been devoted to investigating the attitudinal and behavioral consequences of direct mail advertising in general and of charitable direct mail in particular. An exception is the study of Korgaonkar, Karson and Akaah (1997), who investigate consumers' attitudes towards direct marketing solicitations. They find that even though some consumers enjoy direct mailings (for example in the case of catalogs) and describe them as informative and entertaining, many consumers view them as useless junk mail.

\section{Charitable direct mailing irritation}

Recently there have appeared some studies establishing that too many direct mailings in a short period of time may have a negative long-run effect on the attitude towards the mailing company, for example caused by irritation (Diamond and Noble 2001, Elliott and Speck 1998). Besides the displeasure incurred by the content of an advertisement (as studied by Aaker and Bruzzone 1985, for example), the sheer frequency of exposure may cause annoyance (Bruce 1995; Greyser 1973; Zajonc 1968). Additionally, indirect evidence for frequency induced irritation ${ }^{3}$ is presented by Naik and Piersma (2002), who

\footnotetext{
${ }^{3}$ Irritation, as a negative affective response, can also result in other contexts, see for example Pruyn and Smidts (1998) for a study of irritation caused by waiting times.
} 
find that cumulative direct mailing exposures cause irritation which erodes goodwill towards the company.

This negative effect of direct mailings may be even stronger in the case of charitable direct mailings as opposed to, for example, catalogs. This is because charitable requests suggest obligation and there are no obvious immediate personal benefits of responding for the recipient (Rothschild 1979). Individuals do not like to be confronted with such appeals (Diamond and Noble 2001), and their tendency to get irritated by high charitable mail frequencies may be much stronger than it is with regular direct mail. Indeed, Francis and Holland (1999) show that consumers have much stronger feelings about charitable direct mail than other types of direct mail and that charitable direct mail results in more irritation.

\section{Behavioral consequences}

High frequencies of direct mailings can cause unfavorable attitudinal and emotional responses. Naik and Piersma (2002) argue that the role of marketing communications and their effects on attitudinal variables in direct mailing response is generally ignored. This is particularly striking as it is generally agreed that consumer attitudes influence consumer behavior (Fishbein and Ajzen 1975). For example, perceived advertising clutter might reduce direct mail effectiveness (Stafford, Lippold and Sherron 2003), possibly due to ad avoidance (Elliott and Speck 1998). In sum, individuals who feel they receive too much direct mail may have lower intentions to respond to the mail they receive.

Moreover, Diamond and Noble (2001) show that high frequencies of unsolicited donation requests can induce defensive responses. Hence, super-saturation might occur (Leeflang, Wittink, Wedel and Naert 2000, p.68) and the marginal returns to excessive direct mailings might not only be decreasing, but could well become negative. Hence, excessive charitable direct mail could cause so much irritation that donations actually decrease.

Although the literature provides clear evidence of direct mailing induced irritation and has suggested serious consequences for direct mailing effectiveness, no study has linked direct mailing irritation with actual donating behavior. It is precisely this that we study in our paper. 


\section{Data}

We created a unique data set by combining data from three different sources. The three sources all address a specific problem inherent to this type of study and subject matter.

First, to avoid social desirability bias, which is a common problem when measuring social behavior such as charitable donating, we need objective behavioral data on actual levels of charitable donating. Second, in order to solve potential endogeneity issues, that is, people who donate more are also likely selected for a next round of mailings, we need to ensure exogenously determined variation in the number of mailings received by individuals. To this end, we set up a field experiment. Third, we need a survey to measure the subjective construct "irritation", which cannot be objectively measured from behavioral data.

It is important to note the time periods that are relevant to our measures. The experimental mailings and all information on past behavior relate to the period preceding the survey, so they all potentially affect irritation and stated donation behavior. Actual future donating behavior concerns the period following our survey, so it can logically be only a consequence and not a cause of our other measures, and most importantly, of irritation. This setup of our data collection efforts hence permits us to draw strong conclusions about the direction of causality in our analysis.

\section{Source 1: Charity databases}

\section{Motivation}

To study the relationships between charitable direct mailings, irritation and donating behavior, an obvious method would be to conduct a survey. A well-known problem with this type of research, however, is the possibility of a social desirability bias in self-stated data. Charitable donating is a typical example of this phenomenon. People tend to overestimate their true behavior in an attempt to appear more socially acceptable (Burt and Popple, 1998). Hence, we cannot be certain that people actually donate as much as they say they do. 
In addition, it is quite plausible that people would overestimate the number of charitable direct mailings they receive, simply because they are annoyed by them. Hence, if there is an effect of the perception of the number of mailings received on irritation, and this perception does not correspond to reality, there is not much that charities can do about it. They can only directly influence the true number of mailings, not people's perceptions.

Hence, for reliable and practically relevant inference on the impact of direct mailing induced irritation on donating behavior, we need objective data about the driver of irritation, that is, the actual mailing frequencies, and about the consequences of irritation, that is, actual donating behavior. Both constructs would be poorly captured by self-stated measures. Of course, it would be very hard, if not impossible, to obtain objective individual level data on total mailing frequencies and donations across all charities. For this study, however, we fortunately have access to the databases of five very large charity organizations in the Netherlands, covering about $30 \%$ of the total charitable direct-mailing revenues annually. This allows us to create a unique dataset for a large sample of active donators containing the number of direct mailings received and the actual donations made.

\section{Measures}

From our combined dataset of the five charities, we can construct an abundance of different measures. However, for the purpose of this study we focus on three main constructs. The first is donating behavior. We want to investigate the effect of irritation on future donating behavior. Thus, we need to construct a measure of donating behavior following the moment that we measure irritation.

As a single-donation event is often not representative of total donating behavior (Diamond and Gooding-Williams, 2002), we consider an aggregate donating behavior measure. Thus, to measure actual future donating behavior, we use the total donation to the five charities in our study in the four months after we surveyed irritation.

The next construct we extract from this dataset is mailing frequency. To study the effect of mailing frequency on irritation, we need a measure of the mailing frequency prior to our irritation measurement. To this end, we measure past mailing frequency as 
the total number of direct mailings an individual has received from the five charities in the twelve months preceding the irritation measurement.

Finally, not every individual in our dataset is a donator to all five charities. Privacy regulations in the Netherlands allow charities to store only addresses of individuals that have donated at least once to their organization in the past. Hence, the vast majority of the mailings are sent to individuals that are their own donators. ${ }^{4}$ If someone donates to multiple charities, he or she may also expect to receive more direct mailings. To control for this type of heterogeneity, we construct dummy variables indicating to which charities someone donates, and thus which charities are, so to say, active. In addition, we measure the total amount donated and the number of donations in the twelve months preceding the irritation measurement to capture individual differences in donating activity.

\section{Sample}

Our charities concern three different issues. Charities 2 and 4 are in health issues, charities 1 and 5 are for international aid and charity 3 concerns social welfare. These charities are among the largest charities and together they receive almost $30 \%$ of the total revenues from direct mail that the 440 certified charities in the Netherlands collect. Our dataset covers mailings and donations for these charities during more than three and a half years, spanning January 2004 until August 2007.

\section{Source 2: Natural field experiment}

\section{Motivation}

Instead of randomly selecting individuals from their list of addresses to send a mailing, charities generally apply target selection (Bult, Scheer and Wansbeek, 1997). They aim to select the targets that are most likely to respond. As it is generally believed that past behavior is the best predictor for future behavior (Rossi, McCulloch and Allenby 1996), most companies use measures like Recency, Frequency, and Monetary value (RFM) to implement target selection. Essentially, this amounts to predicting future behavior using past behavior.

\footnotetext{
${ }^{4}$ Charities also send out direct mailings to acquire new donators, but the number of such mailings is negligible in comparison to the mailings sent out to donators on their house lists.
} 
A consequence of such behavior-driven target selection rules is that the best donators also receive most direct mails. This means that the number of mailings an individual receives from a charity depends on his past donating behavior. When modeling the relationship between charitable direct mailings, irritation and donating behavior, the number of direct mailings is therefore endogenous. In a sense the sample is not fully random anymore, and parameter estimates may be biased, see Donkers, Paap, Jonker and Franses (2006) or Manchanda, Rossi and Chintagunta (2004).

\section{Experimental design}

To avoid potential endogeneity we design a controlled field experiment. ${ }^{5}$ Our goal is to introduce exogenous variation in the number of mailings that individuals receive, so that we can draw reliable and unbiased conclusions about the relations between direct mailings, irritation and donating behavior. It is important to note that the individuals are not aware of the fact that they participate in a field experiment. Such experiments are known as natural field experiments; see List and Reiley (2008) for the benefits of this approach.

In our field experiment, the five charities have sent experimental mailings to their donators. Note that the content of these experimental mailings was typical for the charities. The experimental feature of the mailings relates to the mailing schedule that was designed by us to circumvent the endogeneity problem. To ensure a relatively large impact of the experimental mailings on irritation, the experimental mailings were all sent out within the last week of March 2007. This period represents a typical period in terms of regular mail pressure. The precise week was selected not to coincide with existing mailing campaigns of one of the charities because a single charity sending multiple mailings in one week to one donator would not be considered as realistic. ${ }^{6}$ To maintain realism the mailings sent to each individual were randomly assigned to the days in that week.

\footnotetext{
${ }^{5}$ Other recent field experiments in marketing include, among others, Heiman and Lowengart (2008), Shang, Reed II and Croson (2008) and Simester et al. (2009).

${ }^{6}$ Note that the main aim of a controlled natural field experiment is to investigate human behavior in a realistic setting.
} 
To be able to uncover the effect of mailing frequency and the resulting irritation, we vary the number of mailings donators receive from the charities. As charities can only send mailings to their previous donators, we select existing donators of a charity to receive experimental mailings of that charity (see Karlan and List (2007) for a similar setup).

Our experimental manipulation consists of sending a number of experimental mailings in addition to the charities' regular mailing schedule. We select a control group that will receive no experimental mailings and a treatment group that will receive experimental mailings. Within the treatment group we systematically vary the number of experimental mailings the individuals receive. Note that each charity will send at most one experimental mailing to each individual, as sending multiple mailings in a short period of time is unrealistic. The number of experimental mailings is therefore equal to the number of charities that send an experimental mailing. The participating charities perceived our proposed increase in mail pressure as extremely strong. In fact, one charity (number 6) eventually refused participation because of the large increase in mail pressure, even after an initial agreement. In addition, we had to allow the charities to inform their call-centers about the experiment, so that they could reassure worried donators that they were part of a scientific experiment and that charities had not suddenly started to bombard them with mailings. ${ }^{7}$

\section{Sample}

For the experiment we restrict our attention to that part of the population that meets the following criteria. First, we only consider individuals that have been active in the past eighteen months, where active means they have donated at least once. Consultation with our charities has resulted in this definition, also because they themselves use it when performing analyses and selections on their databases. Next, we eliminate individuals that have had an ongoing direct debit authorization with at least one of the charities in the past eighteen months. The donation behavior of these individuals is rather different as many payments will be unnoticed and charities send them fewer requests for additional donations. Furthermore, these individuals are highly valuable to the charities and we were

\footnotetext{
${ }^{7}$ None of the charities received calls like this.
} 
therefore requested not to bother them with extra mailings. Finally, some donators communicated to the charities that they want to receive a limited number of mailings a year and these individuals were also excluded.

Insert Table 1 about here

The left part of Table 1 depicts our experimental design, that is, the distribution of subjects across the experimental treatments. An individual can be a donator to one charity or to all five charities, but these individuals are not included here, hence we focus on moderate givers. For the donators to only one charity, we do not expect to find distinct results with regards to irritation, as the number of mailings can only be increased with one. For the donators to five charities, our participating charities requested that they would not be bothered with a survey.

Donators to $n$ charities can only receive a maximum of $n$ experimental mailings, and hence not all cells in Table 1 are filled. We initially allocated 600 individuals to each feasible experimental cell, but population size restrictions, detailed below, resulted in lower values for donators active with three or more charities. To illustrate the setup, from the individuals that are donator to three charities, 600 receive 1 experimental mailing, 600 receive 2 experimental mailings and 600 receive 3 experimental mailings. Of course, there are various possible charity combinations for a particular number of charities. We choose to distribute the subjects equally across the different charity combinations, so that each charity sends the same number of experimental mailings. We decided to have a relatively large control group, as this is the reference group for all treatments within a 'number of active charities' condition. We randomly assigned donators from the relevant populations to both the control group and the various treatment conditions.

For some charity combinations an insufficient number of donators exist to have each treatment condition filled completely. This resulted in a smaller size of the control group for donators active with three charities and overall smaller group sizes for donators who are active with four charities. Finally, the actual distribution of donators over the various treatment conditions deviates slightly from the design as the charities did not 
send out 18 from the 10840 mailings we had scheduled. This was mainly the result of the charities continuously updating the status of their donators.

\section{Source 3: Survey}

\section{Motivation}

Subjective constructs such as emotions and attitudes cannot be measured objectively from observed behavioral data. Of course, we can make conjectures about an emotion or attitude from its behavioral consequences, but alternative explanations and underlying processes cannot be ruled out this way. Hence, to find out how people feel we have to ask them. Therefore, we conduct a survey to measure irritation regarding charitable direct mailings.

\section{Measures}

Data were collected through a questionnaire which was conducted amongst the subjects in the experiment via mail three weeks after the experiment took place. Two main constructs for this study were measured through the survey, that is, irritation and donating behavior. Although we measure true actual donating behavior through the charities' databases, we decided to measure stated donating behavior as well. We can then compare our results based on stated and actual donation behavior and investigate whether social desirability bias might affect our conclusions.

Irritation was measured by four items which are all related to direct mailing induced irritation (intrusiveness, annoyance, quantity, boredom) and were partly based on Akaah, Korgaonkar and Lund (1995). For each item, respondents indicated their degree of agreement/disagreement on a 7-point Likert scale. Note that this measure of irritation captures irritation induced both by the experimental mailings and by the regular mailing activities of all charities. When studying the consequences of irritation on donating behavior, we effectively use all naturally existing variation in irritation plus the variation that resulted from the additional experimental mailings.

For future donating behavior, we use donation intent, that is, intended total donation to charities in the next year. This was measured in seven categories, ranging 
from "Less than 25 Euros" to "More than 1000 Euros". The exact measures are presented in Appendix A.

To minimize common-method bias the two constructs were measured using different methods. That is, we used a multi-item Likert scale for irritation and an ordinal scale for donating behavior. Furthermore, we investigated common-method variance using Harman's one-factor test (Podsakoff and Organ, 1986). As factor analysis in our case does not indicate a single 'general' factor that accounts for the majority of the covariance in our variables, serious common-method bias is unlikely to be present here.

\section{Sample}

We sent the questionnaire to 4230 donators, split about equally across treatment (2050 questionnaires) and control groups (2180 questionnaires). These precise numbers were obtained from a procedure that ensured an equal distribution of questionnaires across all possible experimental conditions in combination with the set of charities for which the donators are active. In particular the latter makes this a nontrivial task, as there are, for example, ten combinations of three active charities out of the five charities participating.

We use all questionnaires with complete information on irritation and donation intentions that we received within two weeks after they were sent out. This resulted in a final sample of 1002 respondents, which amounts to a reasonably high response rate of $23.7 \%$. The right part of Table 1 presents the distribution of the respondents across the experimental conditions. Note that none of the respondents noticed a connection of the survey with the experiment. That is, in the space for general comments, no one indicated a recent unusual high number of mailings.

\section{Data preparation}

We applied confirmatory factor analysis on items intended to measure irritation. The results indicate a good fit as indicated by a non-significant Chi-square, a RMSE of 0.04 and NFI, CFI and AGFI all exceeding 0.98. Reliability of the composite irritation measure was satisfactory (Cronbach's alpha of 0.83). As the factor loadings of all four items are very similar, we use average scores to form the composite irritation variable. As a robustness check, we also did all analyses with factor regression scores for irritation 
instead of average scores, but this did not alter any conclusions. Finally, 7 of the 1002 respondents did not answer the question on donation intentions. These respondents were ignored in our analysis of stated response behavior.

\section{Descriptive statistics for the combined dataset}

Our final dataset consists of 11740 individuals that were in our experimental design, of which 1002 individuals provided useful responses to our survey. Perceived irritation is quite high, as, on a 7-point scale, it obtains an average value of 5.32 (standard deviation is 1.42). We find that 812 individuals (81.0\%) have an average score higher than 4 across the four items, meaning they are (at least somewhat) irritated by charitable direct mailings. Moreover, 152 individuals (15.2\%) scored the maximum on all items and accordingly they are very irritated. Thus, irritation is indeed substantial.

In the twelve month period before the survey, individuals received an average of 1.23 (standard deviation is 0.44) direct mailings per month in total from the five charities in our study, about one mailing every three weeks. The differences between the charities are rather small, with charities sending between 0.3 and 0.5 mailings per month to their donators, on average. This may seem low for US standards, but charities in the Netherlands have a much lower mailing frequency that in the US. Importantly, the number of experimental mailings sent out represents a substantial increase in mail pressure, with donators receiving up to three times as many mailings during that month as usual. $^{8}$

\section{Insert Table 2 about here}

As expected, when someone donates to more charities, he or she receives more direct mailings, see Table 2. And, when a person donates to more charities, stated donating behavior also increases. At the same time, the average amount of money donated in response to a mailing is fairly stable, so also the total amount actually donated increases. Note that actual and stated behavior are not directly comparable, as the first is

\footnotetext{
${ }^{8}$ We expect people to evaluate mail pressure within a relatively short horizon, making a comparison with the monthly mail pressure more relevant than with, say, an annual mail frequency.
} 
measured by the total donation amount in the four months after the survey, so this is in real money terms, while the second is measured on an ordinal scale of 1 to 7 representing categories with increasingly higher amounts intended to donate. Appendix B provides means by experimental condition and overall means and standard deviations of, and correlations between, our most important variables.

\section{Empirical results}

To uncover the relationships between charitable direct mailings, irritation and donating behavior we estimate various models. The first relates irritation associated with charitable direct mailings to the received number of these mailings. Thus, we study the effect of charitable mailings on irritation. Do more mailings indeed lead to more irritation? Or are people simply irritated with charitable requests in general, no matter how many mailings they receive? Next, we estimate a model for both stated and actual donating behavior, relating them to irritation and charitable direct mailings. Given that people tend to be quite irritated about charitable direct mailings, does this irritation reduce their responsiveness to (future) requests? As people might reduce the number of responses, the total amount of money donated, or both, we investigate the impact of irritation on each. To gain more insight in potential differences across charities, we also estimate a model for the total amount donated to each of the charities individually.

\section{Insert Table 3 about here}

\section{Irritation}

In Table 3 we present the results of a linear regression of irritation on charitable direct mailings in the past year, where we distinguish between mailings from the experiment and mailings according to the charities' mailing strategies. For the regular mailings, there is systematic variation in the number of direct mailings people receive, depending on the number of active charities. In addition, donators have chosen to donate to a given number of charities, depending at least in part on their overall attitude towards charities. To control for these systematic influences, we add five dummy variables, one for activity of 
each of the five charities. We further control for individual heterogeneity through the inclusion of the individual's age, gender and the total amount donated to the participating charities in the twelve months preceding the survey.

First of all, we find that the experimental mailings increase irritation. At the same time, the mailings the charities have sent according to their mailing strategies do not increase irritation. A likely explanation is target selection used by charities for their mailing campaigns. In particular, the zero effect we find could well be caused by mailings that do cause irritation, but they were sent to individuals that have a low level of irritation to start with. This is in contrast to our experimental mailings, which have been sent out randomly.

The other individual characteristics show that females are more irritated, as are older people. The active dummies for the charities provide a mixed picture. A test for equal coefficients for these dummies, however, shows that they can all be pooled $(\mathrm{F}=1.42, \mathrm{p}=0.22)$. Estimation of a single coefficient, in that case for the total number of charities, then results in a non-significant impact of being active with more charities. Finally, we studied whether age and gender affect the impact of the experimental mailings on irritation by including the corresponding interactions. The results of this model confirmed the positive influence of our experimental mailings on irritation $(\mathrm{B}=0.414, \mathrm{p}=0.018)$. Furthermore, we find no significant moderation by gender but a significant moderation by age $(B=-0.005$, $\mathrm{p}=0.038$ ). That is, as one gets older the impact of mailings on irritation reduces.

\section{Donation behavior}

Next we investigate the effect of irritation and mailings on donating behavior. Our combined data set of both self-stated and actual data allows us to study potential differences between the two. For example, people may overestimate their true charitable donations in an attempt to appear more socially acceptable. This could nullify a potential negative effect of irritation on donations.

As self-stated behavior is measured on an ordered categorical scale with unequal distances between the category thresholds, we estimate an ordered logit model for donation intention for next year. 


$$
\text { donation } *=X^{\prime} \beta+\varepsilon
$$

with

$$
\begin{array}{ll}
\text { donation }=1 & \text { if donation* } \leq \mu_{1} \\
\text { donation }=j & \text { if } \mu_{j-1}<\text { donation }{ }^{*} \leq \mu_{j}, j=2, \ldots, 6 \\
\text { donation }=7 & \text { if } \mu_{6}<\text { donation } *
\end{array}
$$

Here donation* is a latent variable and $\mu_{1}$ to $\mu_{6}$ are unobserved thresholds that satisfy $\mu_{1}<\mu_{2}<\ldots<\mu_{5}<\mu_{6}$. Furthermore, $X$ contains all relevant explanatory variables and $\varepsilon$ has a cumulative standard logistic distribution. For the actual amount donated and the number of donations made in the four months after the survey, we apply linear regression.

Insert Table 4 about here

Table 4 presents the estimation results for the two measures of actual behavior and for stated donating behavior. We find that the effect of irritation, although negative in all models, is never significantly different from zero. ${ }^{9}$ In other words, we find no indications that irritation reduces donations. Although people are highly annoyed by the high direct mailing frequencies of charities, this does not seem to affect their donating behavior. Even though our sample contains just over 1,000 observations, nonsignificance could result from a lack of precision. The point estimate of -0.544 , however, also suggests limited economic impact. To be more precise, the increased irritation resulting from one additional mailing is only 0.067 (cf. Table 3). The economic costs of the resulting irritation are then less than 4 cents for all five charities together during a four month period. As our charities represent $30 \%$ of total charitable revenues, the market level costs amount to a mere 13 cents. Next we take a very conservative point of view by calculating the costs based on the end points of the 95\% confidence intervals for the effect of mailings on irritation and that of irritation on donations. Still we find that the revenue loss incurred by the charities in our sample due to irritation is well below half the

\footnotetext{
${ }^{9}$ About $15 \%$ of the respondents scored the highest value on the irritation scale. To check for a potential ceiling effect, we included a dummy for this answer, in order to allow its value in the model to exceed the stated value. The dummy proved insignificant.
} 
immediate revenues they obtained by sending an extra (experimental) mailing, which is about 1 euro 80 cents.

Continuing with the results for the actual amount of money donated, we find a negative, but also not significant, direct effect of the experimental mailings. This would be in line with decreasing marginal effects of mailings, as more mailings will negatively impact the revenues from future mailings, in line with the cannibalization effects reported in for example Van Diepen, Donkers and Franses (2009).

As expected, the amount donated in the past is highly predictive of future donations. Curiously, we also find a significant and positive effect of the number of mailings in the year before the survey on donating behavior after the survey. This unlikely reflects a direct causal relationship. An explanation might again lie in the potential endogeneity of the number of mailings in the past year. Most target selection is based on the idea that past behavior is the best predictor for future behavior. Through target selection, charities send most direct mailings to the most generous donators in the past, who will also be generous donators in the future. The number of mailings received hence seems to capture a part of donator generosity that is not captured by the amount donated in the past. Finally, the effects of the dummy variables for activity of the different charities are all negative, but with only one being significant. This suggests that donating to multiple charities reduces the total amount donated, everything else constant.

The results for the number of donations made are fairly similar. As already mentioned, irritation does not reduce the number of donations, so irritation also does not cause individuals to redistribute their donations into fewer but larger donations. As one could expect, we find that the number of donations made in the past year has a stronger link with the future number of donations than with the total amount donated, while the reverse holds for the amount the individual donated in the past. The charity activity dummies are all insignificant, suggesting that donating to multiple charities reduces the amount of money per donation, but not the total number of donations.

Remarkably, and contrary to expectations, we find hardly any differences when comparing the results for self-stated behavior with those for actual total donation. Of course, because of differences in scale and type of the dependent variable, we cannot directly compare the parameter estimates in the two models, but we can compare the 
main conclusions about the direction and significance of the effects. Also for stated behavior we find no effect of irritation. Furthermore, the experimental mailings do not affect stated donating behavior, while past behavior predicts well. In sum, social desirability bias does not appear to bias the conclusion in our study that donating behavior is mainly determined by attitudinal factors, and that it is not affected by feelings of irritation regarding charitable direct mailings.

\section{Mere-measurement effects}

Our study so far has not provided evidence for a negative impact of irritation on revenues of charitable direct mailings. The literature on the mere-measurement effect suggests an indirect approach to testing the presence of a negative impact of irritation. With our survey we asked respondents to think about a number of issues relating to direct mail pressure, including their actual perceived mail pressure, their perception of the information content of mailings, in addition to the measures of future donating behavior and irritation used in our main analysis. Our survey thus required respondents to process these aspects of charitable direct mailings and to state how much they expect to donate in the future. Processing the negative aspects might make them stronger (Dholakia and Morwitz, 2002) and more available (Janiszewski and Chandon, 2007), possibly lowering future donation activities. At the same time, stating intentions about performing (socially) desirable activities, like donating to charity, might increase future donations (Spangenberg, 1997). In particular, asking about responding to a charitable request has been shown to affect the response tendency (Obermiller and Spangenberg, 2000). Recently, Liu and Aaker (2008) found that asking for intentions about the amount donated, instead of the act of donating, reduces the amount donated.

To study the impact of sending out and responding to the survey, we repeat the analysis on the drivers of actual choice behavior, but we now exclude the variables we obtained from the survey, that is, irritation, age and gender. This enables us to compare the donation behavior of individuals who received a survey $(\mathrm{N}=4230)$ with those who did not $(\mathrm{N}=7510)$. Within the group of individuals who received the survey we distinguish between donators who responded to the survey $(\mathrm{N}=1002)$ and those who did not $(\mathrm{N}=3228)$. 
Insert Table 5 about here

The estimation results for the model described above for the amount donated and the number of donations made are presented in Table 5. The focal variables in this table are the dummies for receiving the survey and for responding to it. Both have no significant influence on observed future behavior. Receiving the survey and even actively processing and returning it does not affect future behavior, neither the total amount nor the number of donations. We also estimated a model where we included interactions of the explanatory variables with the measurement dummies, but all interactions proved insignificant. So, we find a zero net effect of the survey. Still, this might result from the cancellation of a negative effect of measuring irritation and a positive effect of measuring donation intentions, but this cannot be identified.

The other estimates in Table 5 are more precise and hence more effects are statistically significant, as the model is estimated on a much larger sample. In particular, we now find evidence for decreasing marginal revenues, as receiving experimental mailings reduces future donation behavior. These mailings cannibalize future revenues. This is clearly only a short term effect, as having donated more in the past year is indicative of donating more now. The same holds for the number of mailings received and the number of donations made.

\section{Discussion and conclusion}

The main conclusions from our study can be easily summarized. Individuals feel irritated by the amount and frequency of charitable direct mailings, but these negative feelings are not propagated into stated nor actual donating behavior. We could obtain these clear-cut findings due to the fact that five of the largest charities in the Netherlands allowed us to control in a field experiment the number of mailings that individuals received. In contrast, in a non-experimental setting one would have had a hard time disentangling the consequences of target selection rules typically used by charities and the actual received messages and subsequent reactions. Our results confirm the need for a proper accounting 
of endogeneity, as in most models we find vastly different and even opposite effects of past regular mailings and of the experimental mailings.

Our analysis of this unique database does support a common wisdom amongst managers at charities. They always felt that irritation could arise but also that donations were not slowing down. A main message from this study could be that irritation is not a key emotional driver when it comes to responding to charities' direct mailings. It is quite conceivable that such mailings induce feelings of guilt and of social responsibility that are stronger than irritation. In addition, donators cannot blame the eventual beneficiaries of the money they donate, that is, say, the children in $3^{\text {rd }}$ world countries or those suffering from a particular disease, for the unpleasant behavior of the charity.

This separation of beneficiary and charity and the resulting disconnection between the requester and the recipient of the money seems to result in a failure of market-like correction mechanisms. If a regular store provides poor service, you simply go to shop elsewhere. In case all charities send many mailings, as they tend to do, you cannot go elsewhere to help the beneficiaries. With the charities sending more and more mailings, but the donators having nowhere else to go, this is a typical case for government intervention or at least self-regulation from the charities. In particular, caps could be imposed on the number of solicitations sent out or on the amount of irritation induced by charitable direct mailings. The rise of the number of private initiatives to provide aid to those in need, even suggests that more and more donators have found an alternative means to reach the final beneficiaries without being irritated.

Note that our findings do not refute those of Diamond and Noble (2001). They found that direct mail pressure and the resulting negative affective responses like irritation cause recipients to use defensive actions. Our results show that these defensive mechanisms are not very effective. Similar to regular advertising, where people think they are not affected as they develop defensive strategies (Speck and Elliott 1997), people also seem to think they have found an effective way of handling charitable mailings, but still keep on donating in response to at least some of them.

Our study does have one limitation which we feel opens up an important avenue for further research. In the field experiment, we manipulated mail pressure by having five different charities send additional direct mailings on top of their regular mailing strategy 
in a single week. Although this did boost the mail pressure substantially, it did so in only a limited period of time. Further research could extend the duration of the variation in mail pressure to see whether our results continue to hold in these circumstances. It is, however, important to note that our experiment already did increase irritation among the recipients, so our manipulation has been effective in that respect. 


\section{Tables}

\section{Table 1:}

Number of individuals across experimental treatments and number of survey responses.

\begin{tabular}{lrrrrrrrr}
\hline & \multicolumn{3}{c}{ Experimental design } & \multicolumn{3}{c}{ Surveys received } \\
\hline Number of active charities & 2 & 3 & 4 & 2 & 3 & 4 \\
\hline Control & 0 mailings & 2400 & 2394 & 1770 & 147 & 181 & 138 \\
& & & & & & & \\
\multirow{2}{*}{ Treatment } & 1 mailing & 600 & 600 & 544 & 64 & 49 & 64 \\
& 2 mailings & 600 & 600 & 544 & 53 & 53 & 66 \\
& 3 mailings & - & 600 & 544 & - & 69 & 54 \\
& 4 mailings & - & - & 544 & - & - & 64 \\
\hline
\end{tabular}




\section{Table 2:}

Descriptive statistics for individuals with different numbers of active charities (Standard deviations are in parentheses)

\begin{tabular}{lccc}
\hline $\begin{array}{l}\text { Number of active } \\
\text { charities }\end{array}$ & $\begin{array}{l}\text { Average number of } \\
\text { direct mailings per } \\
\text { month }\end{array}$ & $\begin{array}{l}\text { Average amount } \\
\text { donated per mailing }\end{array}$ & $\begin{array}{l}\text { Stated donating } \\
\text { behavior }\end{array}$ \\
\hline 2 & $0.80(0.23)$ & $4.56(9.24)$ & $4.76(1.55)$ \\
3 & $1.20(0.26)$ & $4.68(8.10)$ & $5.17(1.46)$ \\
4 & $1.65(0.30)$ & $4.61(6.94)$ & $5.27(1.34)$ \\
\hline
\end{tabular}


Table 3:

Estimation results for irritation (sample size is 1002)

(Standard errors are in parentheses)

\begin{tabular}{|c|c|c|c|}
\hline Intercept & 3.831 & $* * *$ & $(0.278)$ \\
\hline Number of experimental mailings & 0.067 & $*, \mathrm{a}$ & $(0.034)$ \\
\hline Number of mailings past year & 0.003 & & $(0.014)$ \\
\hline Female & 0.241 & $* *$ & $(0.095)$ \\
\hline Age & 0.014 & $* * *$ & $(0.003)$ \\
\hline Amount donated past year & 0.000 & & $(0.000)$ \\
\hline Number of donations past year & -0.020 & & $(0.014)$ \\
\hline Active charity 1 & 0.140 & & $(0.133)$ \\
\hline Active charity 2 & 0.198 & $*$ & $(0.115)$ \\
\hline Active charity 3 & 0.158 & & $(0.117)$ \\
\hline Active charity 4 & 0.249 & * & $(0.141)$ \\
\hline Active charity 5 & -0.035 & & $(0.115)$ \\
\hline
\end{tabular}


Table 4:

Estimation results for actual and self-stated donating behavior (sample size is 1002)

(Standard errors in parentheses)

\begin{tabular}{|c|c|c|c|c|c|c|}
\hline \multirow[b]{3}{*}{ Intercept } & \multicolumn{4}{|c|}{ Actual behavior } & \multicolumn{2}{|c|}{ Stated behavior } \\
\hline & \multicolumn{2}{|c|}{ Total donation } & \multicolumn{2}{|c|}{ Number of donations } & \multirow[b]{2}{*}{---} & \multirow[b]{3}{*}{$(0.041)$} \\
\hline & 17.232 & $(21.806)$ & -0.154 & $(0.270)$ & & \\
\hline Irritation & -0.544 & $(0.986)$ & 0.008 & $(0.027)$ & 0.012 & \\
\hline $\begin{array}{l}\text { Number of experimental } \\
\text { mailings }\end{array}$ & -0.855 & $(1.100)$ & -0.045 & $(0.037)$ & 0.048 & $(0.047)$ \\
\hline Number of mailings past year & 1.490 & $(0.940)$ & $0.033 * *$ & $(0.016)$ & 0.020 & $(0.019)$ \\
\hline Female & -0.677 & $(3.650)$ & -0.040 & $(0.084)$ & $-0.257 * *$ & $(0.123)$ \\
\hline Age & -0.236 & $(0.236)$ & 0.000 & $(0.003)$ & -0.004 & $(0.005)$ \\
\hline Amount donated past year & $0.207 * * *$ & $(0.041)$ & $-0.001 * *$ & $(0.000)$ & $0.013 * * *$ & $(0.003)$ \\
\hline Number of donations past year & 0.285 & $(0.627)$ & $0.316 * * *$ & $(0.016)$ & -0.014 & $(0.026)$ \\
\hline Active charity 1 & -1.228 & $(2.823)$ & 0.019 & $(0.127)$ & 0.034 & $(0.171)$ \\
\hline Active charity 2 & $-4.912 * *$ & $(2.374)$ & $-0.197 *$ & $(0.113)$ & $0.282 *$ & $(0.148)$ \\
\hline Active charity 3 & -5.610 & $(6.050)$ & -0.190 & $(0.117)$ & -0.103 & $(0.155)$ \\
\hline Active charity 4 & -2.502 & (3.670) & -0.035 & $(0.127)$ & -0.240 & $(0.184)$ \\
\hline Active charity 5 & -9.852 & $(6.843)$ & -0.134 & $(0.116)$ & -0.067 & $(0.151)$ \\
\hline
\end{tabular}


Table 5:

Estimation results for the mere-measurement effect on actual donation behavior (sample size is 11740)

(Standard errors are in parentheses)

\begin{tabular}{|c|c|c|c|c|}
\hline \multirow[b]{3}{*}{ Intercept } & \multicolumn{4}{|c|}{ Actual behavior } \\
\hline & \multicolumn{2}{|c|}{ Total donation } & \multicolumn{2}{|c|}{ Number of donations } \\
\hline & $-2.667 * *$ & $(1.141)$ & $-0.114 * * *$ & $(0.042)$ \\
\hline Dummy survey received & 2.046 & $(1.882)$ & 0.017 & $(0.025)$ \\
\hline Dummy responded to survey & 0.061 & $(0.725)$ & 0.040 & $(0.046)$ \\
\hline Number of experimental mailings & $-0.716 * *$ & $(0.360)$ & $-0.049 * * *$ & $(0.010)$ \\
\hline Number of mailings past year & $0.804 * * *$ & $(0.172)$ & $0.028 * * *$ & $(0.005)$ \\
\hline Amount donated past year & $0.166 * * *$ & $(0.038)$ & $0.000 * * *$ & $(0.000)$ \\
\hline Number of responses past year & $1.140 * *$ & $(0.440)$ & $0.302 * * *$ & $(0.005)$ \\
\hline Active charity 1 & -0.355 & $(1.107)$ & 0.011 & $(0.035)$ \\
\hline Active charity 2 & $-2.338 * *$ & $(1.156)$ & $-0.153 * * *$ & $(0.031)$ \\
\hline Active charity 3 & $-2.425 * *$ & $(0.959)$ & $-0.177 * * *$ & $(0.031)$ \\
\hline Active charity 4 & $-2.475 *$ & $(1.295)$ & -0.041 & $(0.036)$ \\
\hline Active charity 5 & $-2.631 * *$ & $(1.025)$ & $-0.120 * * *$ & $(0.030)$ \\
\hline
\end{tabular}




\section{References}

Aaker, D.A. and D E. Bruzzone (1985). Causes of Irritation in Advertising. Journal of Marketing, 49 (2), 47-57.

Abdy, M. and J. Barclay (2001). Marketing Collaborations in the Voluntary Sector. International Journal of Nonprofit and Voluntary Sector Marketing, 6 (3), 215-230.

Akaah, I.P., PK. Korgaonkar and D Lund (1995). Direct Marketing Attitudes. Journal of Business Research, 34 (3), 211-219.

Andreoni, J. (2006). Philanthropy, in Handbook of Giving, Reciprocity and Altruism. SC. Kolm and J.M. Ythier, eds., Amsterdam: North Holland, 1201-1269.

Bruce, I. (1995). Do Not-for-profits Value Their Customers and Their Needs?. International Marketing Review, 12 (4), 77-84.

Bult, J.R., H. van der Scheer and T. Wansbeek (1997). Interaction between target and mailing characteristics in direct marketing, with an application to health care fund raising. International Journal of Research in Marketing, 14(4), 301-308.

Burt, C.D.B. and J.S. Popple (1998). Memorial distortions in donation data. Journal of Social Psychology, 138 (6), 724-733.

Diamond, W.D. and S. Gooding-Williams (2002). Using Advertising Constructs and Methods to Understand Direct Mail Fundraising Appeals. Nonprofit Management \& Leadership, 12 (3), 225-242.

Diamond, W.D. and S.M. Noble (2001). Defensive Responses to Charitable Direct Mail Solicitations. Journal of Interactive Marketing, 15 (3), 2-12. 
Dholakia, U.M. and V.G. Morwitz (2002). The Scope and Persistence of MereMeasurement Effects: Evidence from a Field Study of Customer Satisfaction Measurement. Journal of Consumer Research, 29 (2), 159-167.

Direct Marketing Association (2007). DMA 2007 Statistical Fact Book: The Definitive Source for Direct Marketing Benchmarks. New York: Direct Marketing Association.

Donkers, B., R. Paap, J. Jonker and P.H. Franses (2006). Deriving Target Selection Rules from Endogenously Selected Samples. Journal of Applied Econometrics, 21 (5), 549-562.

Elliott, M.T. and P.S. Speck (1998). Consumer Perceptions of Advertising Clutter and Its Impact across Various Media. Journal of Advertising Research, 38 (1), 29-41.

Fishbein, M. and I. Ajzen (1975). Belief, Attitude, Intention, and Behavior: An Introduction to Theory and Research. Reading, MA: Addison-Wesley.

Francis, N. and N. Holland (1999). The Diary of a Charity Donor: an Exploration of Research Information from the Royal Mail Consumer Panel and Mail Characteristics Survey. International Journal of Nonprofit and Voluntary Sector Marketing, 4 (3), 217223.

Greyser, S.A. (1973). Irritation in Advertising. Journal of Advertising Research, 13 (1), 3-10.

Heiman, A. and O. Lowengart (2008). The effect of information about health hazards on demand for frequently purchased commodities. International Journal of Research in Marketing, 25(4), 310-318.

Janiszewski, C. and E. Chandon (2007). Transfer-Appropriate Processing, Response Fluency, and the Mere Measurement Effect. Journal of Marketing Research, 44 (2), 309323. 
Karlan, D. and J.A. List (2007). Does Price Matter in Charitable Giving? Evidence from a Large-Scale Field Experiment. American Economic Review, 97 (5), 1774-1793.

Korgaonkar, P.K., E.J. Karson and I.P. Akaah (1997). Direct Marketing Advertising: The Assents, the Dissents, and the Ambivalents. Journal of Advertising Research, 37 (5), 4155.

Leeflang, P.S.H., D.R. Wittink, M. Wedel and P.A. Naert (2000). Building Models for Marketing Decisions. Dordrecht: Kluwer.

List, J.A. and D. Reiley (2008). Field Experiments, The New Palgrave Dictionary of Economics. Eds. Steven N. Durlauf and Lawrence E. Blume, Palgrave Macmillan, 2008.

Liu, W. and J. Aaker (2008). The Happiness of Giving: The Time-Ask Effect. Journal of Consumer Research, 35 (3), 543-557.

Manchanda, P., P.E. Rossi and P.K. Chintagunta (2004). Response Modeling with Nonrandom Marketing-Mix Variables. Journal of Marketing Research, 41 (4), 467-478.

Naik, P.A. and N. Piersma (2002). Understanding the Role of Marketing Communications in Direct Marketing. Econometric Institute Report EI 2002-13, Econometric Institute, Erasmus University Rotterdam.

NFP Synergy (2004). Disgusted or Delighted: What Does the Concern the Public About Charities?. http://www.nfpsynergy.net/reportdownload.php?pdf=Disgusted or delighted March 2004.pdf

Obermiller, C., and E.R. Spangenberg (2000). Improving Telephone Fundraising by Use of Self-Prophecy. International Journal of Nonprofit and Voluntary Sector Marketing, 5 (4), 365-372.

Podsakoff, P.M. and D.W. Organ (1986). Self-Reports in Organizational Research: Problems and Prospects. Journal of Management, 12 (4), 531-544. 
Pruyn A. and A. Smidts (1998). Effects of waiting time on the satisfaction with the service: beyond objective time measures. International Journal of Research in Marketing, 15(4), 321-334.

Rossi, P.E., R.E. McCulloch and G.M. Allenby (1996). The Value of Purchase History Data in Target Marketing. Marketing Science, 15 (4), 321-340.

Rothschild, M.L. (1979). Marketing Communications in Nonbusiness Situations or Why It’s So Hard to Sell Brotherhood Like Soap. Journal of Marketing, 43(2), 11-20.

Sargeant, A. and J. Kähler (1999). Returns on Fundraising Expenditures in the Voluntary Sector. Nonprofit Management \& Leadership, 10 (1), 5-19.

Shang, J., A. Reed II and R. Croson (2008). Identity congruity effects on donations. Journal of Marketing Research, 45(3), 351-361.

Simester, D.I., Y. Hu, E. Brynjolfsson and E.T. Anderson (2009). Dynamics of Retail Advertising: Evidence from a Field Experiment. Economic Inquiry, forthcoming.

Spangenberg, E.R. (1997). Increasing Health Club Attendance Through Self-Prophecy. Marketing Letters, 8 (1), 23-32.

Speck, P.S. and M.T. Elliott (1997). Predictors of Advertising Avoidance in Print and Broadcast Media. Journal of Advertising, 26 (3), 61-76.

Stafford, M.R., E.M. Lippold and C. Todd Sherron (2003). The Contribution of Direct Mail Advertising to Average Weekly Unit Sales. Journal of Advertising Research, 43 (2), 172-179.

TNS NIPO (2003). Goede Doelen Doen Goed Werk! Zolang Ze Mij Maar Niet Lastig vallen. TNS NIPO Publications, http://www.tns-nipo.com/pages/nieuws-pers-vnipo.asp? 
file=persvannipolgoededoelen03.htm.

Van Diepen, M., B. Donkers and P.H. Franses (2009). Dynamic and Competitive Effects of Direct Mailings: A Charitable Giving Application. Journal of Marketing Research, 46 (1), 120-133.

Zajonc, R.B. (1968). Attitudinal Effects of Mere Exposure. Journal of Personality and Social Psychology, 9 (Supp. 2 Pt. 2), 1-27.

Zielske, H.A. (1959). The Remembering and Forgetting of Advertising. Journal of Marketing, 23 (3), 239-243. 


\section{Appendix A}

Irritation and stated donating behavior were measured using the following questions.

1. To what extent do you agree with the following statements? (1=strongly disagree, 7=strongly agree)
a) It irritates me that I am approached by charities without my consent
b) The frequency at which I am approached by charities annoys me
c) I find letters of charities annoying
d) I am bored by the large amounts of letters from charities I receive

2. How much do you expect to donate to charity next year?

Less than $€ 25$

$\square € 25-€ 50$

$\square € 50-€ 100$

$\square € 100-€ 250$

$\square € 250-€ 500$

$\square € 500-€ 1000$

$\square \quad$ More than $€ 1000$ 


\section{Appendix B}

Table B.1 Means for the most important variables by experimental condition.

\begin{tabular}{|c|c|c|c|c|c|c|c|c|c|c|c|c|}
\hline $\begin{array}{l}\text { Number of active } \\
\text { charities } \\
\text { Number of } \\
\text { experimental } \\
\text { mailings }\end{array}$ & 0 & 1 & 2 & 0 & 1 & 2 & 3 & 0 & 1 & 2 & 3 & 4 \\
\hline Irritation & 5.02 & 5.35 & 5.01 & 5.30 & 5.41 & 5.34 & 5.46 & 5.34 & 5.51 & 5.46 & 5.56 & 5.69 \\
\hline $\begin{array}{l}\text { Total amount } \\
\text { donated after survey }\end{array}$ & 11.07 & 9.25 & 8.21 & 18.73 & 16.32 & 18.68 & 16.89 & 28.42 & 24.97 & 23.31 & 27.40 & 24.70 \\
\hline $\begin{array}{l}\text { Responses After } \\
\text { Survey }\end{array}$ & 0.71 & 0.71 & 0.60 & 1.22 & 1.24 & 1.12 & 1.07 & 1.96 & 1.89 & 1.82 & 1.70 & 1.68 \\
\hline $\begin{array}{l}\text { Stated donation } \\
\text { behavior }\end{array}$ & 4.70 & 4.84 & 4.80 & 5.11 & 5.29 & 5.26 & 5.16 & 5.32 & 5.37 & 5.21 & 5.15 & 5.25 \\
\hline $\begin{array}{l}\text { Number of } \\
\text { Experimental } \\
\text { Mailings }\end{array}$ & 60.43 & 61.34 & 63.55 & 64.55 & 66.42 & 63.48 & 63.74 & 66.56 & 67.12 & 67.10 & 64.38 & 67.00 \\
\hline Age & 0.49 & 0.56 & 0.41 & 0.36 & 0.37 & 0.30 & 0.36 & 0.33 & 0.26 & 0.27 & 0.42 & 0.30 \\
\hline Female & 2.49 & 2.42 & 2.42 & 4.29 & 4.20 & 4.17 & 3.99 & 6.12 & 6.32 & 6.04 & 6.31 & 6.22 \\
\hline $\begin{array}{l}\text { Number of } \\
\text { Responses Past Year }\end{array}$ & 39.87 & 35.82 & 49.14 & 68.07 & 59.89 & 67.17 & 62.19 & 91.57 & 87.59 & 81.50 & 101.30 & 97.20 \\
\hline $\begin{array}{l}\text { Total amount } \\
\text { donated past year }\end{array}$ & 9.63 & 9.29 & 9.11 & 14.65 & 14.35 & 14.15 & 13.87 & 20.29 & 19.90 & 19.58 & 19.22 & 19.27 \\
\hline $\begin{array}{l}\text { Number of Mailings } \\
\text { Past Year }\end{array}$ & 5.02 & 5.35 & 5.01 & 5.30 & 5.41 & 5.34 & 5.46 & 5.34 & 5.51 & 5.46 & 5.56 & 5.69 \\
\hline
\end{tabular}

Note: Sample sizes vary by condition and by variable, see Table 1 for details. 
Table B.2 Descriptive statistics and bivariate correlations for the most important variables.

\begin{tabular}{|c|c|c|c|c|c|c|c|c|c|c|c|c|c|}
\hline & & \multirow[t]{2}{*}{ Mean } & \multirow[t]{2}{*}{ StdDev } & \multicolumn{10}{|c|}{ Correlations } \\
\hline & & & & 1 & 2 & 3 & 4 & 5 & 6 & 7 & 8 & 9 & 10 \\
\hline 1 & Irritation & 5.32 & 1.42 & 1.00 & -0.01 & 0.02 & -0.01 & $0.09 * * *$ & $0.13^{* * *}$ & 0.05 & 0.02 & 0.02 & $0.08 * * *$ \\
\hline 2 & $\begin{array}{l}\text { Total amount } \\
\text { donated after survey }\end{array}$ & 18.59 & 44.93 & -0.01 & 1.00 & $0.48^{* * *}$ & $0.16^{* * *}$ & $0.02 * *$ & -0.03 & -0.03 & $0.28 * * *$ & $0.49 * * *$ & $0.20 * * *$ \\
\hline 3 & $\begin{array}{l}\text { Number of } \\
\text { Responses After } \\
\text { Survey }\end{array}$ & 1.26 & 1.65 & 0.02 & $0.48 * * *$ & 1.00 & $0.19 * * *$ & $0.04 * * *$ & $0.08 * *$ & $-0.06^{*}$ & $0.67 * * *$ & $0.21^{* * *}$ & $0.38 * * *$ \\
\hline 4 & $\begin{array}{l}\text { Stated donation } \\
\text { behavior }\end{array}$ & 5.09 & 1.45 & -0.01 & $0.16^{* * *}$ & $0.19 * * *$ & 1.00 & 0.03 & 0.01 & $-0.08 * *$ & $0.24 * * *$ & $0.34 * * *$ & $0.18^{* * *}$ \\
\hline 5 & $\begin{array}{l}\text { Number of } \\
\text { Experimental } \\
\text { Mailings }\end{array}$ & 0.92 & 1.23 & $0.09 * * *$ & 0.02 & $0.04 * * *$ & 0.03 & 1.00 & 0.05 & -0.04 & $0.11 * * *$ & $0.06^{* * *}$ & $0.17 * * *$ \\
\hline 6 & Age & 64.36 & 12.71 & $0.13^{* * *}$ & -0.03 & $0.08^{* *}$ & 0.01 & 0.05 & 1.00 & $-0.14^{* * *}$ & $0.11^{* * *}$ & 0.03 & $0.11^{* * *}$ \\
\hline 7 & Female & 0.37 & 0.48 & 0.05 & -0.03 & $-0.06^{*}$ & $-0.08 * *$ & -0.04 & $-0.14^{* * *}$ & 1.00 & $-0.07 * *$ & $-0.05^{*}$ & $-0.13^{* * *}$ \\
\hline 8 & $\begin{array}{l}\text { Number of } \\
\text { Responses Past Year }\end{array}$ & 4.34 & 3.56 & 0.02 & $0.28 * * *$ & $0.67 * * *$ & $0.24^{* * *}$ & $0.11^{* * *}$ & $0.11^{* * *}$ & $-0.07 * *$ & 1.00 & $0.36 * * *$ & $0.50 * * *$ \\
\hline 9 & $\begin{array}{l}\text { Total amount } \\
\text { donated past year }\end{array}$ & 66.93 & 118.55 & 0.02 & $0.49 * * *$ & $0.21^{* * *}$ & $0.34^{* * *}$ & $0.06 * * *$ & 0.03 & $-0.05^{*}$ & $0.36^{* * *}$ & 1.00 & $0.21^{* * *}$ \\
\hline 10 & $\begin{array}{l}\text { Number of Mailings } \\
\text { Past Year }\end{array}$ & 14.74 & 5.24 & $0.08^{* * *}$ & $0.20 * * *$ & $0.38 * * *$ & $0.18^{* * *}$ & $0.17^{* * *}$ & $0.11^{* * *}$ & $-0.13^{* * *}$ & $0.50 * * *$ & $0.21^{* * *}$ & 1.00 \\
\hline
\end{tabular}

***,***: significant at a 10\%, 5\%, and 1\% level, respectively 


\section{Publications in the Report Series Research* in Management}

\section{ERIM Research Program: “Marketing"}

2008

Experts' Stated Behavior

Youssef Boulaksil and Philip Hans Franses

ERS-2008-001-MKT

http://hdl.handle.net/1765/10900

The Value of Analogical Reasoning for the Design of Creative Sales Promotion Campaigns: A Case-Based Reasoning Approach

Niek A.P. Althuizen and Berend Wierenga

ERS-2008-006-MKT

http://hdl.handle.net/1765/11289

Shopping Context and Consumers' Mental Representation of Complex Shopping Trip Decision Problems

Benedict G.C. Dellaert, Theo A. Arentze and Harry J.P. Timmermans

ERS-2008-016-MKT

http://hdl.handle.net/1765/11812

Modeling the Effectiveness of Hourly Direct-Response Radio Commercials

Meltem Kiygi Calli, Marcel Weverbergh and Philip Hans Franses

ERS-2008-019-MKT

http://hdl.handle.net/1765/12242

Choosing Attribute Weights for Item Dissimilarity using Clikstream Data with an Application to a Product Catalog Map Martijn Kagie, Michiel van Wezel and Patrick J.F. Groenen

ERS-2008-024-MKT

http://hdl.handle.net/1765/12243

The Effect of Superstar Software on Hardware Sales in System Markets

Jeroen L.G. Binken and Stefan Stremersch

ERS-2008-025-MKT

http://hdl.handle.net/1765/12339

Sales Growth of New Pharmaceuticals Across the Globe: The Role of Regulatory Regimes

Stefan Stremersch and Aurélie Lemmens

ERS-2008-026-MKT

http://hdl.handle.net/1765/12340

When Intelligence is (Dys)Functional for Achieving Sales Performance

Willem J. Verbeke, Frank D. Belschak, Arnold B. Bakker, and Bart Dietz

ERS-2008-034-MKT

http://hdl.handle.net/1765/12633

Path Dependencies and the Long-term Effects of Routinized Marketing Decisions

Paul Farris, Willem J. Verbeke, Peter Dickson and Erjen van Nierop

ERS-2008-035-MKT

http://hdl.handle.net/1765/12634

Does Irritation Induced by Charitable Direct Mailings Reduce Donations?

Merel van Diepen, Bas Donkers and Philip Hans Franses

ERS-2008-036-MKT

http://hdl.handle.net/1765/12704 
Brain Mechanisms of Persuasion: How "Expert Power" Modulates Memory and Attitudes

Vasily Klucharev, Ale Smidts and Guillén Fernández

ERS-2008-038-MKT

http://hdl.handle.net/1765/12784

Moderating Factors of Immediate, Dynamic, and Long-run Cross-Price Effects

Csilla Horváth and Dennis Fok

ERS-2008-042-MKT

http://hdl.handle.net/1765/12901

Why, How and When Do Prices Land? Evidence from the Videogame Industry

Carlos Hernandez-Mireles, Dennis Fok and Philip Hans Franses

ERS-2008-044-MKT

http://hdl.handle.net/1765/12900

Situation-Based Shifts in Consumer Web Site Benefit Salience: The Joint Role of Affect and Cognition

Sonja Wendel and Benedict G.C. Dellaert

ERS-2008-050-MKT

http://hdl.handle.net/1765/13179

Including Item Characteristics in the Probabilistic Latent Semantic Analysis Model for Collaborative Filtering

Martijn Kagie, Matthijs van der Loos and Michiel van Wezel

ERS-2008-053-MKT

http://hdl.handle.net/1765/13180

Cross-National Logo Evaluation Analysis: An Individual Level Approach

Ralf van der Lans, Joseph A. Cote, Catherine A. Cole, Siew Meng Leong, Ale Smidts, Pamela W. Henderson, Christian

Bluemelhuber, Paul A. Bottomley, John R. Doyle, Alexander Fedorikhin, M. Janakiraman, B. Ramaseshan,

and Bernd $H$. Schmitt

ERS-2008-055-MKT

http://hdl.handle.net/1765/13181

Sales and Sincerity: The Role of Relational Framing in Word-of-Mouth Marketing

Mirjam A. Tuk, Peeter W.J. Verlegh, Ale Smidts and Daniel H.J. Wigboldus

ERS-2008-056-MKT

http://hdl.handle.net/1765/13183

Interpersonal Relationships Moderate the Effect of Faces on Person Judgments

Mirjam A. Tuk, Peeter W.J. Verlegh, Ale Smidts and Daniel H.J. Wigboldus

ERS-2008-057-MKT

http://hdl.handle.net/1765/13185

Evaluative Conditioning 2.0: Referential versus Intrinsic Learning of Affective Value

Steven Sweldens, Stijn M.J. van Osselaer, and Chris Janiszewski

ERS-2008-062-MKT

http://hdl.handle.net/1765/13612

Gender Identity Salience and Perceived Vulnerability to Breast Cancer

Steven Sweldens, Stefano Puntoni, and Nader Tavassoli

ERS-2008-063-MKT

http://hdl.handle.net/1765/13613

The Emotional Information Processing System is Risk Averse: Ego-Depletion and Investment Behavior

Bart De Langhe, Steven Sweldens, Stijn M.J. van Osselaer, and Mirjam Tuk

ERS-2008-064-MKT

http://hdl.handle.net/1765/13614 
The Moderating Roles of Relationship Quality and Dependency in Retailers' New Product Adoption Decisions Yvonne M. van Everdingen, Laurens M. Sloot, and Peter C. Verhoef

ERS-2008-065-MKT

http://hdl.handle.net/1765/13615

Modeling Global Spill-Over of New Product Takeoff

Yvonne M. van Everdingen, Dennis Fok, Stefan Stremersch

ERS-2008-067-MKT

http://hdl.handle.net/1765/13616

Measuring Productivity Change without Neoclassical Assumptions: A Conceptual Analysis

Bert M. Balk

ERS-2008-077-MKT

http://hdl.handle.net/1765/13876

One Analogy Can Hide Another: Physics and Biology in Alchian's "Economic Natural Selection" Clément Levallois

ERS-2008-083-MKT

http://hdl.handle.net/1765/14278

* A complete overview of the ERIM Report Series Research in Management: https://ep.eur.nl/handle/1765/1

ERIM Research Programs:

LIS Business Processes, Logistics and Information Systems

ORG Organizing for Performance

MKT Marketing

F\&A Finance and Accounting

STR Strategy and Entrepreneurship 